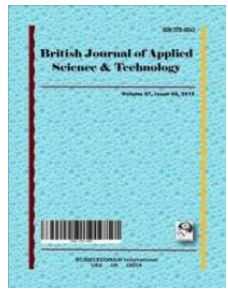

British Journal of Applied Science \& Technology

18(5): 1-16, 2016; Article no.BJAST.30737

ISSN: 2231-0843, NLM ID: 101664541

SCIENCEDOMAIN international

www.sciencedomain.org

\title{
Radio Frequency Identification and Internet of Things: A Fruitful Synergy
}

\author{
O. T. Arulogun ${ }^{1}$, A. S. Falohun ${ }^{1}$ and N. O. Akande ${ }^{2^{*}}$ \\ ${ }^{1}$ Department of Computer Science and Engineering, Ladoke Akintola University of Technology, \\ Ogbomoso, Nigeria. \\ ${ }^{2}$ Department of Computer Science, Landmark University, Omuaran, Nigeria.
}

Authors' contributions

This work was carried out in collaboration between all authors. Author OTA initiated the thoughts behind the review, designed the framework used for the review, carried out the initial correction of the manuscript and wrote the abstract. Authors ASF and NOA searched related literatures used and carried out the review work with author OTA. All authors read and approved the final manuscript.

Article Information

DOI: 10.9734/BJAST/2016/30737

Editor(s):

(1) Kleopatra Nikolopoulou, School of Education, University of Athens, Athens, Greece.

Reviewers:

(1) A. John, Pondicherry University, India.

(2) Vikram Puri, GNDU Regional Center, Jalandhar, India. (3) Prajakta Pavan Shirke, Sandip Institute of Technology and Research Centre, Nashik, Maharashtra, India. (4) Somayya Madakam, National Institute of Industrial Engineering (NITIE), Vihar Lake, Mumbai, India. Complete Peer review History: http://www.sciencedomain.org/review-history/17616

Review Article

Received $28^{\text {th }}$ November 2016 Accepted 6 $6^{\text {th }}$ January 2017 Published $26^{\text {th }}$ January 2017

\section{ABSTRACT}

The interconnection of devices, mechanical and digital machines, objects, animals or people with the ability to transfer data over a network without requiring human-to-human or human-to-computer interaction known as Internet of Things (loT) can only be successfully achieved with the incorporation of some existing wireless technologies especially Radio Frequency Identification (RFID). RFID leverages on its ability to establish a wireless communication between its transponders or tags attached to objects; when these tags are interrogated by RFID transceivers or readers, identification indicators that could further provide needed information are deduced. This paper presents an overview of the possible synergy between RFID and IoT as it promises to expand the Internet and networks to places such as home, manufacturing floors, energy grids, healthcare facilities, agricultural farms and plantations, transportation, etc. Besides a brief introduction to the operating principles behind the technology, a detail review of the application of 
RFID technology across current and envisaged fields were carried out. The projection of a promising synergy between loT and RFID technologies was also established. Though, some limitations of both IoT and RFID were uncovered, suggestions on likely improvements were proffered.

Keywords: Internet of things; radio frequency identification; RFID technologies.

\section{INTRODUCTION}

RFID technology has a huge role to play in the actualization of the vision of connecting objects around us to the internet. These objects range from large buildings, industrial plants, planes, cars, machines, any kind of goods, specific parts of a larger system to human beings, animals and plants and even specific body parts of them. The concept behind this is called Internet of Things (loT). The loT paradigm foresees the development of our current environment towards new enriched spaces, such as smart cities, smart homes, smart grid, digital health, intelligent transportation systems, smart home and automated environmental pollution control [1]. The smart object is the building block of the loT vision. By putting intelligence into everyday objects, they are turned into smart objects that are not only able to collect information from the environment and interact or control the physical world, but can also interconnect to each other through Internet to exchange data and information [2]. As documented in [3], loT makes objects intelligent and facilitates data sharing between them. For illustration, a lightweight platform can be deployed in a home to orchestrate several connected objects, such as the refrigerator, the lights, and the heating system. On a broader scale, a smart city may benefit its development and management from new loT solutions that can handle thousands of sensors, ease their maintenance, recalibration and, more importantly, analyze the data that they produce $[4,5]$. This paper presents an overview of the extent to which RFID can empower things around us in order to achieve the vision of IoT. The background of RFID technology was presented including its application areas. Possible solutions were also proffered to the identified limitations of RFID and loT.

\section{WHY RFID AND IOT SYNERGY?}

The target of IoT is not limited to objects alone, it targets automating every human daily activities and processes such as Transportation and logistics domain, Healthcare domain, Smart environment (home, office, plant) domain, Personal and social domain. While loT does not assume a specific communication technology, wireless communication technologies will play a major role, and in particular, Wireless Sensor Networks (WSNs) will proliferate many applications and many industries. The small, rugged, inexpensive and low powered WSN sensors will bring the loT to even the smallest objects installed in any kind of environment, at reasonable costs. Integration of these objects into IoT will be a major revolution of WSNs [6]. loT visions recognize that the term loT implies a much wider idea than the idea of a mere objects identification. According to [7], RFID still stands at the forefront of the technologies driving the loT idea. This is as a result of the RFID maturity, low cost, and strong support from the business community. However, it is clear that a wide portfolio of device, network, and service technologies will eventually build up the loT. Near Field Communications (NFC) and Wireless Sensor and Actuator Networks (WSAN) together with RFID are recognized as "the atomic components that will link the real world with the digital world" [7]. A comparison between RFID systems, wireless sensor networks, and RFID sensor networks was carried out in Table 1 [8].

Table 1. Comparison between RFID systems, wireless sensor networks, and RFID sensor networks

\begin{tabular}{lllllll}
\hline Technology & Communication & Range $(\mathbf{m})$ & Power & Lifetime & Size & Standard \\
\hline RFID & Asymmetric & 10 & Harvested & Indefinite & Very & ISO18000 \\
& & & & & small & \\
WSN & Peer-to-peer & 100 & Battery & $<3$ years & Small & EEE \\
RSN & Asymmetric & 3 & Harvested & Indefinite & Small & None \\
\hline
\end{tabular}


The following can be observed from Table 1;

(i). RFID systems are the very small size and the very low cost. Furthermore, their lifetime is not limited by the battery duration;

(ii). Wireless sensor networks are the high radio coverage and the communication paradigm, which does not require the presence of a reader (communication is peer-to-peer whereas, it is asymmetric for the other types of systems);

(iii). RFID sensor network are the possibility of supporting sensing, computing, and communication capabilities in a passive system.

\section{RFID OPERATION FUNDAMENTALS}

An RFID system consists of RFID tags or transponders, an RFID reader or transceivers, and middleware (software component). The identification of the RFID tag takes place by the reader over the wireless medium or air while RFID tags are the carry object-identifying data which comes in different shapes, dimensions, and have different capabilities. All RFID tags are made up of a radio antenna and a microchip built on a substrate as shown in Fig. 1.

Furthermore, RFID tags are of three basic types:

(a). Active RFID tags which are powered by a battery (b). Passive RFID tags which are powered by the RFID reader signal.

(c). Semi-passive tags which do contain batteries but the batteries do not take part in the transmission of the radio signal. So, they are not considered as active tags.

RFID tags are very cheap and the passive versions are able to generate the necessary power for waking the tag from a sleep state. Unlike active tags, RFID passive tags have such a low distance range of operation is because of the fact that these tags operate on the principle of electromagnetic induction which itself is relatively weak with increasing distance. Then there is also a path loss between the transmitting and receiving antennas to consider [9]. A comparison between the two major types of RFID tags (Passive and active) as carried out in [10] is illustrated in Table 2.

The main functions of the RFID reader are to activate the RFID tag, structure its communication sequence, and transfer data between the software component and the RFID tag. Features such as contactless communication, i.e. making the connection, and performing anti-collision and authentication procedures, are handled entirely by the reader [11].

According to [12], readers can be classified based on how the readers were affixed, designed and the technology used as illustrated in Table 3.

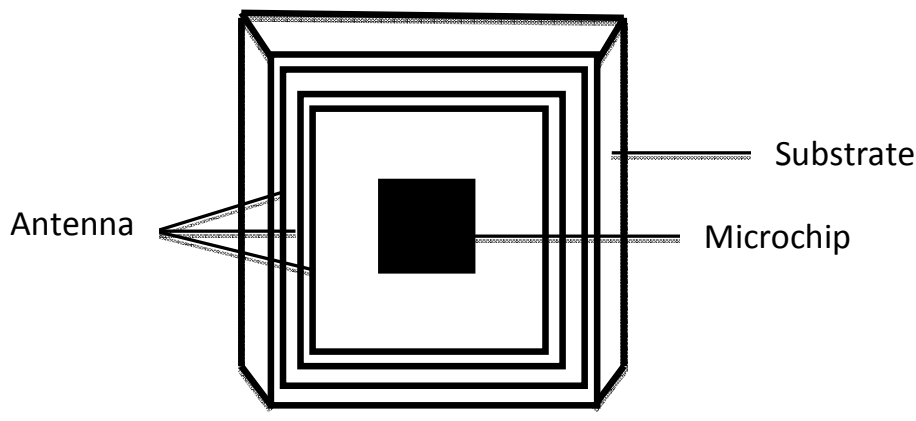

Fig. 1. Components of RFID tag

Table 2. Comparism between the types of tags

\begin{tabular}{lllll}
\hline & Features & Passive & Semi-Passive & Active \\
\hline 1. & Power Source & Harvesting RF energy & Battery & Battery \\
2. & Communication & Response only & Response only & Respond or initiate \\
3. & Max Range & $10 \mathrm{~m}$ & $>100 \mathrm{~m}$ & $>100 \mathrm{M}$ \\
4. & Relative Cost & Least expensive & More expensive & Most expensive \\
\hline
\end{tabular}


Table 3. Classification of RFID readers

\begin{tabular}{ll}
\hline 1. By design and technology used \\
\hline Read & $\begin{array}{l}\text { - only reads data from the tag } \\
\text { - usually a micro-controller-based unit with a wound output coil, peak detector } \\
\text { hardware, comparators, and firmware designed to transmit energy to a tag and } \\
\text { read information back from it by detecting the backscatter modulation }\end{array}$ \\
& $\begin{array}{l}\text { - different types for different protocols, frequencies and standards exist } \\
\text { Read/write } \quad \text { reads and writes data from/on the tag }\end{array}$ \\
\hline 2. By fixation of the device \\
\hline Stationary & $\begin{array}{l}\text { The device is attached in a fixed way, for example at the entrance gate, } \\
\text { respectively at the exit gate of products }\end{array}$ \\
Mobile & In this case the reader is a handy, movable device.
\end{tabular}

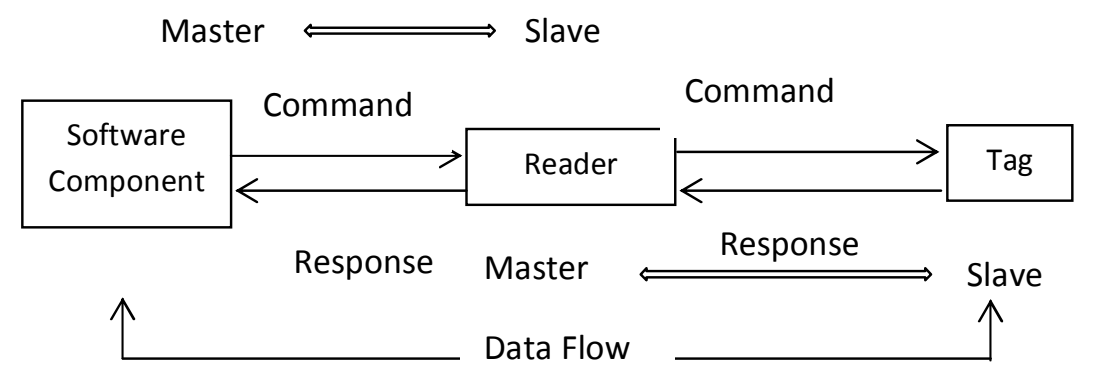

Fig. 2. Master-slave principle between software component, reader and tag [11]

Write and read operations involving a reader are performed on the basis of the master-slave principle as shown in Fig. 2. This means that all reader and transponder activities are initiated by the software component. In a hierarchical system structure, the software component represents the master, while the reader, as the slave, is only activated when write/read commands are received from the application software. To execute a command from the application software, the reader first enters into communication with a transponder. The reader now plays the role of the master in relation to the transponder. The transponder therefore only responds to commands from the reader and is never active independently.

The software component serves as the backend for the RFID technology; it is made up of a database and an application interface. When new information is received, it adds it to the database and if needed performs some computation and updates the database. In some cases, the software component may be integrated with the reader itself. For instance, in the case of a RFID based student attendance management system, the tag may contain certain information about the student while the reader may read the information and save them in a backend database for record purposes.
RFID technology is not perfect in all ramifications as tags can become faulty if not handled properly, hence to ensure maximum operation of RFID tags, they must be handled with care. In addition to this, if RFID tags are not correctly attached or placed, its readings may be corrupted, therefore, technical expertise is needed while fixing the tag. Furthermore, harsh environmental conditions can affect RFID tags, hence, they should be carefully placed at places where they cannot be immersed in water of not directly exposed to sunlight for a long period of time. Also, RFID readings may not be accurate if the tag and reader are not within the expected range or coverage area, so, the knowledge of the expected read range must be strictly adhered to while fixing both tag and reader. Possible virus attack was reported in [13], it was submitted that virus may affect the backend database on which readings of the RFID readers are being saved, therefore, measures must be put in place to prevent this so as not to be caught unaware. Moreover, depending on the field of application, certain privacy or security concerns can affect the accuracy of data generated by the RFID system. In instances where they are used to ensure compliance of workers to some working conditions or rules, maximum cooperation and adherence of workers in this instance must be solicited for; else the intention and purpose for 
using it will be jeopardized. In addition to this, unauthorized persons must be prevented from having access to the information provided by the RFID tags or readers either by reading from or writing into the tags, encryption measures can be put in place to ensure that even if the data were accessed it will be meaningless for the intruder.

\section{RFID BASED IOT APPLICATION AREA}

Potentialities offered by the loT make possible the development of a huge number of applications using RFID Technology. In recent years, an abundance of solutions has emerged to interconnect smart objects for systems with different scales and objectives using RFID technology. Such instances include:

\subsection{Transportation and Logistics}

Integrating RFID into cars, trains, buses and bicycles have gradually improved transportation across cities. It has facilitated how humans communicate with these transport media likewise how cars and other transport media communicate with themselves. With sensors and technology like RFID, useful information can be retrieved from cars for processing and onward transmission in refined forms to users of public transit. A first relevant example of an industrial IoT application is the logistics and supply chain management. RFIDs can be attached to objects and used to identify materials and goods, be they garments, furniture, equipment, food, and liquids [14]. Logistic and security issues as a result of attacks on huge number of containers daily involved in the global transportation system was raised in [15]. This led to the design and development of an active RFID-based sealing system by Joint Research Centre (JRC) of the European Commission, this is done with an aim to increase supply chain security. In particular, the seal was designed to minimize the tampering possibility of a standard container, by sealing both its doors at the same time. The seal has a main plastic body linked to an external cable by two connections. One end of the cable is fixed to the body and cannot be taken out, otherwise the seal would break and the unauthorized opening detected. The other cable end can be inserted in the main body, secured by a ring nut and can be opened.

The electronic components of the system were embedded into both the main body and the external cable. The active RFID circuit was placed in the seal body, together with a passive low frequency (LF) transponder reader, working at the frequency of $125 \mathrm{kHz}$. A passive RFID chip was also installed in the removable end of the external cable. The passive transponder was used to guarantee the proper closure of the seal: when the end of the external cable is inserted and the seal is closed, the passive system reads the Unique Identifier (UID) of the passive tag and transmits it to the active transponder. Every active circuit is linked to the UID of a specific passive transponder. The pairing mechanism will be set during the seal production process and ensures that the seal is correctly closed with the right cable (the pairing is signaled through a buzzer at seal closure). Once the seal is closed every attempt of opening it will be detected from the passive RFID system components and signaled to the active circuit logic. The external cable represents another critical component of the system: Possible attacks to the system could be done cutting the shielded cable and re-closing it after the container opening. The solution adopted to avoid this problem is the use of a conductive wire inside the external cable. This wire gives an electrical connection to the electronic circuit placed in the main body, which is continuously monitored by the electronics. Any attempt of cutting the cable would result in a loss of electrical continuity for the electronic seal, and thus an alarm would be triggered. Every tampering attempt will result in a change of the seal state and will be automatically recorded in a memory section of the electronic card. In general, the seal memory will contain information on any possible operation (authorized opening, unauthorized opening or cable cutting) done on the seal during its working time and after its correct closure (i.e. after that the correct pairing between the passive tag and the active seal electronics has been performed). When the seal memory becomes full it is necessary to reset it by using the portable reading system. An operative field test was organized in order to verify the actual capabilities and security features of the active RFID sealing system. It was showed that the real-time tampering revelation feature greatly increases the security of the whole supply chain.

Also, a deficiency in products motion control which has led huge financial and time treats was identified in [16]. During storage, large industrial production goes through three main stages: reception to the warehouse, storage and shipment from the warehouse. The movement of these industrial products is often made by bridge 
cranes or mobile loaders. In most cases the technique used for goods transportation is not equipped with means of position determining so the organization of products motion control at the warehouse with staff resources is always unreachable. Errors such as incorrect placement of the product on admission, incorrect movement between storage areas and shipment of incorrect product, as a result of these, significant time are wasted and financial treats are possible. To solve these problems, a RFID system for determining the location of large industrial products during transportation was introduced. This was employed to monitor products transportation to the storage area and the items capture from the storage area for onward transportation. This involved mounting a RFID reader on conveyor device and equipping storage areas with labels. This approach was used to determine which of the storage areas a product was last located. For the transported goods, RFID-tags attached to each products helped to determine with high accuracy which products are transporting at the moment, from which storage area and where. During laboratory research the developed method of identification showed $99.6 \%$ accuracy with object identification speed of 0.3-0.7 seconds.

A RFID-based track-and-trace anti-counterfeiting approach which primarily target high-end consumer products was introduced in [17], this records the movements of product items from manufacturers to retailers to ensure high supply chain visibility and to provide evidence for product authentication. This involved assigning a RFID tag to each product item being manufactured. The product item comes with a unique Product Identifier (PID) which is programmed during manufacturing. The RFID tag becomes a physical part of the product item, moving through the supply chain down to the point of sales (POS) at a retail store. The movement of the product item in the supply chain can thus be collected by RFID equipment and synchronized to back-end database in real-time to form an electronic pedigree (e-pedigree). With reference to the accumulated e-pedigree data, all product items are tracked and authenticated at any supply chain nodes, such as manufacturers, wholesalers, distributors and retailers, to ensure the accuracy of product authentication and the integrity of e-pedigrees. Compared with the high value of these products, the software and hardware costs associated with the RFID trackand-trace anti-counterfeiting system was relatively low and practically justifiable. In this regard, the approach was considered economically beneficial and viable for the owners of high-end brand names to implement and operate to combat counterfeiting. The possibility of practical application of RFID technology into the operation of rail freight in relation to the important international projects that may impact on successful implementation of electronic data exchange in international freight transport was introduced in [18]. This was done to increase the quality of information in freight services and also to increase the overall competitiveness in the field of rail freight. This involved assigning RFID tags to all conventional rail wagons and rail lines. The tags will be encoded with information about wagon number, sender, consignee, payer, type of goods, total weight or other information as appropriate to the owner or operator. This will enable the wagon or consignment to be uniquely identified during all transportation processes. The automation of these activities have been showed to safe time at the delivery points and also reduced errors that could emanate from humans during data collection or transmission.

SafeTrack; a model for logistics management based on geo-fencing algorithms and RFID technology was implemented in [19]. The developed model was used by transport companies' $n$ monitoring their fleets. Devices used include mobile devices, RFID tags and Geo-fencing techniques. The model uses a web platform that helps clients to give information about load's shipments, such as origin, final destination, pickup and delivery dates, among others. On the back end, a web platform provides administrative functionalities which is used to view and monitor goods movements. Should there be a deviation from the fixed route, a real time alarm features are incorporated into the SafeTrack system. A study that shows how RFID technology could be used in supply chain processes was conducted in [20], RFID technology uses EPC global network. The model employed an embedded microsystem, RFID, GPRS, GPS and environmental sensors for logistics monitoring. In order to ensure accuracy of inventory data for warehouse operations, an RFID-enabled warehousing management system was introduced in [21]. The system has the capability of interacting with a proposed RFIDenabled automated storage and retrieval mechanism without any human intervention. To maximize efficiency in material-handling operations and minimize operational costs, a selection algorithm was developed within the 
RFID-inventory management system to seek an optimal solution in which it allows a manipulation of RFID-tracked items under pre-defined rules by assigning a priority (in an order if applicable) to one of selected items to travel to a specified collection point. The gate of the warehouse entrance/exit is equipped with an RFID reader; this collects RFID information data of RFIDtagged goods for each incoming or outgoing lorry that passes through the gate. After the process of unloading and unpacking goods (if applicable), each item will be contained in a tote entering into a storage conveyor, namely storage racks. When a specific item is demanded, it can be transferred automatically from a storage rack onto an output conveyor by a pusher device. Each pusher also contains an RFID reader with its own antenna that receives wireless signals sent from each RFID-tagged item in a storage rack. Collection of inventory data by the reader is updated instantly in a warehouse management system through a controller which transmits the collected data via a middleware. The middleware is the software translation layer between an RFID reader and the warehouse management system. Once an instore item is ordered, the RFID-based inventory management system has capability to carry out an automatic check on information data of the item in database. Once the ordered item is identified by the RFID-based inventory management system, a pusher is activated by a PLC (programmable logic controller) to push the selected item in a tote onto an output conveyor. The item will then be transported by the output conveyor and it travels along an RFID-guided route to a specified destination (i.e., a collection point) for packaging. The RFID-based warehouse inventory database will then be updated as soon as this ordered item is shifted out of the distribution centre in a lorry passing through the gate of the warehouse entrance/exit. The whole process is performed automatically without any human intervention apart from unpacking, labelling and packing operations in the warehouse. A summary of the application of RFID and loT technologies is given in Table 4.

\subsection{Healthcare}

RFID is not only used in transport and logistics, it has also garnered continuous relevance in the healthcare sector. RFID has also been receiving considerable attention in the healthcare industry because it addresses the vexing problem of locating people and things in healthcare operations. The applications of RFID was classified into two major categories based on different objectives in the healthcare industry, they are patient tracking management performance and asset tracking management performance [22]. The first category helps to automate the patient check-in process and other outbound logistical processes (i.e., activities that outsource the service to the customer in a service environment). This involves getting the right patient to the right place at the right time as illustrated in [23]. The second category caters for asset control, assets such as wheelchairs, infusion pumps and crash carts. In the healthcare environment, assets (e.g., equipment and staff) are essential to providing healthcare services to patients. A framework to aid the integration of sensor and RFID tags in healthcare domain was proposed in [24]. The study proposes that any sensor based system for healthcare system must put encompass the following architecture; processing and sensing technology which could be dynamic, static or none; mobility architecture which defines the dynamic spatial relationship between the tags and their readers. This could be Fixed/Fixed, Fixed/mobile, mobile/Fixed or mobile/mobile. Also, the framework must incorporate a relationship architecture which describes the interaction between tags and readers; this could be Master/Dumb-Slave, Master/Smart-Slave, Peer-to-Peer. Finally, an important architectural decision must be made such as if the system will incorporate centralized or distributed structure for data management.

An adaptive knowledge-based system framework for health care using RFID generated information was proposed in [25], the framework helps in the management of bottled gas delivery as well as tracking and tracing surgical equipment and prosthetic ancillaries within a health care environment. Bootled gas are mostly delivered by the pharmacy in an hospital but could be lost in transit or misplaced especially when a patient gets transferred to another hospital and the bottle currently being used by this patient is transported along with the patient to the other hospital. Hence, RFID tags were affixed on these bottles so as to help inform the pharmacy when they are used and when it's time for them to be returned to the pharmacy. Also, ancillaries that are used during the implantation and extraction of prosthesis in humans were monitored using RFID tags. Each of these ancillaries is designed to be used only with a specific brand, model, and type (e.g., hip and knee) of prosthesis because hip prostheses from two different brands or 
even models are sufficiently different that they are not interchangeable. Furthermore, given its infrequent use and the large number of available ancillaries, buying every available ancillary is an expensive proposition both in terms of the cost of acquisition and the resources (e.g., storage, maintenance, and accounting) that are necessary for their proper maintenance and use. This led to the prostheses providers renting ancillaries to hospitals that use their corresponding prosthetic part. Renting naturally translates to the continual movement of these ancillaries among different hospitals throughout their lifetime; this necessitated a means to keep track of their instantaneous location as well as history. Similarly, in the hospital setting, each surgical instrument belongs to a specific set, while instruments from different sets are sterilized together; each instrument is assembled with other instruments in its set after sterilization. That is, each instrument has to be meticulously tracked and traced to ensure instruments that belong together indeed are stored together in their sterile box. RFID technology was also employed in tracking and identifying these surgical instruments.

RFID based Patient Advancement Monitoring System (PAMS) in Operation Theater was implemented in [26]. The system integrated a multiple data entry ports across the multifunctional surgical teams. Data are entered into the system through RFID, bar code, palm digital assistance (PDA), Ultra-Mobile Personal Computer (UMPC), or traditional keyboard at designated checkpoints. Active radio-frequency identification (RFID) tag was used to initiate data demonstration on the computer screens upon a patient's arrival at any particular checkpoint along the advancement pathway. The designed PAMS could manage the progress of operations, patient localization, identity verification, and perioperative care. The workflow monitoring provides caregivers' instant information sharing to enhance management efficiency. Errors involving medication administration can be costly, both in financial and in human terms but proper inpatient medication safety systems can help to reduce such errors in hospitals. Therefore, a comprehensive RFID solution to enhance inpatient medication safety was introduced in [27]. The Inpatient Safety RFID system (ISRFID), takes into account the complete IT infrastructure of a modern hospital. Here, RFID tags are linked to the inpatients (e.g. wristbands) and to the unit-dose medications (e.g. labeled plastic packages) that need to be identified. RFID readers obtain the static identifier of each tag, which was then used as a search index in a database to retrieve all the information linked to the labeled item. The reader was connected to the back-end database via a secure (i.e. authenticated and encrypted) channel in order to access the aforementioned information. The RFID tags used conform to the EPC Gen-2 standard and thus are passive, have a 32-bit password and support an on-board 16-bit PRNG function. A physician that visits the inpatient is expected to diagnose her vy first reading the RFID tag attached to the wristband by using a PDA that includes an RFID reader. After the diagnosis, the physician connects the PDA to his PC to register the prescriptions to the Hospital Information System (HIS). Then, the HIS informs the pharmacy to start the drug package procedure. The system proved to be effective in monitoring an inpatient and drug administration procedure.

Summarily, SMART- a RFID based integrated wireless system for monitoring unattended patients was designed and deployed in [28], it was developed purposely to monitor vital signs and locations of certain classes of ambulatory patients in overcrowded emergency departments and at disaster scenes, both on-site and during transportation. The RFID system was portable, low cost, and have minimal adverse impact on emergency personnel, e.g., by not raising an excessive number of alarms. The SMART (Scalable Medical Alert Response Technology) system integrates wireless patient monitoring (ECG, $\mathrm{SpO}_{2}$ ), geo-positioning, signal processing, targeted alerting, and a wireless interface for caregivers. A prototype implementation of SMART was piloted in the waiting area of an emergency department and evaluated with 145 post-triage patients. These tests were quite useful in testing the whole system. One side effect, however, derived from the fact that the "volunteers" were either technically or medically savvy. As a result, they tended to request features (such as much lighter waist packs) that turned out to be irrelevant to actual patients. Although the volume of eligible patients was low, it was not due to "refusals;" in fact, the patients were more accepting of the system than expected and perceived the monitoring to be useful. Table 5 gives a summary of the various applications of RFID in Healthcare. 
Table 4. RFID/loT usage in transport and logistics

\begin{tabular}{|c|c|c|c|}
\hline $\mathbf{S} / \mathbf{N}$ & Title & System architecture proposed & Principle of operation \\
\hline 1. & $\begin{array}{l}\text { Internet of things architecture for an RFID- } \\
\text { based product tracking business model [14] }\end{array}$ & $\begin{array}{l}\text { Logistics and supply chain } \\
\text { management. }\end{array}$ & $\begin{array}{l}\text { RFID tags were attached to goods and materials for the } \\
\text { purpose of on-site monitoring and tracking. }\end{array}$ \\
\hline 2. & $\begin{array}{l}\text { Improved security for commercial container } \\
\text { transports using an innovative active RFID } \\
\text { system. [15] }\end{array}$ & RFID-based sealing system & $\begin{array}{l}\text { To enforce security on goods being transported, RFID } \\
\text { technology was used to seal containers on a supply } \\
\text { chain. Once the container is opened, a message alert will } \\
\text { be sent to the manufacturer }\end{array}$ \\
\hline 3. & $\begin{array}{l}\text { RFID tag data processing in manufacturing for } \\
\text { track-and-trace anti-counterfeiting [17] }\end{array}$ & $\begin{array}{l}\text { A RFID-based track-and-trace anti- } \\
\text { counterfeiting approach }\end{array}$ & $\begin{array}{l}\text { RFID tag was attached to each product manufactured for } \\
\text { the purpose of monitoring the product as its being } \\
\text { distributed from the manufacturer to retailers. This is } \\
\text { aimed at ensuring supply chain visibility. }\end{array}$ \\
\hline 4. & $\begin{array}{l}\text { Application of RFID Technology in Railway } \\
\text { Transport Services and Logistics Chains [18] }\end{array}$ & $\begin{array}{l}\text { Integrating RFID technology into } \\
\text { the operation of rail freight }\end{array}$ & $\begin{array}{l}\text { RFID tags were fixed to all conventional rail wagons and } \\
\text { rail lines. This helps in keeping records of rails wagon } \\
\text { number, sender, consignee, payer, type of goods, total } \\
\text { weight or other information as appropriate to the owner or } \\
\text { operator. }\end{array}$ \\
\hline 5. & $\begin{array}{l}\text { An intelligent model for logistics management } \\
\text { based on geofencing algorithms and RFID } \\
\text { technology. [19] }\end{array}$ & $\begin{array}{l}\text { SafeTrack; An App. for logistics } \\
\text { management based on geofencing } \\
\text { algorithms and RFID technology }\end{array}$ & $\begin{array}{l}\text { Uses RFID and geo-fencing algorithms to manage } \\
\text { vehicle fleets and cargo }\end{array}$ \\
\hline 6. & $\begin{array}{l}\text { Modern logistics monitoring platform based on } \\
\text { the internet of things [29] }\end{array}$ & $\begin{array}{l}\text { RFID, GPS, GSM/GPRS and WSN } \\
\text { logistics monitoring platform }\end{array}$ & $\begin{array}{l}\text { Technologies used are majorly for data retrieving, } \\
\text { management and dissemination }\end{array}$ \\
\hline 7. & $\begin{array}{l}\text { Embedded devices for supply chain } \\
\text { applications: Towards hardware integration of } \\
\text { disparate technologies [20] }\end{array}$ & $\begin{array}{l}\text { RFID technology usage in supply } \\
\text { chain processes }\end{array}$ & $\begin{array}{l}\text { Proposed a RFID based Electronic Product Code for } \\
\text { continuous and seamless visibility of fixed and mobile } \\
\text { resources from smart enterprises }\end{array}$ \\
\hline 8. & $\begin{array}{l}\text { Application and integration of an RFID- } \\
\text { enabled warehousing management system - a } \\
\text { feasibility study [21] }\end{array}$ & $\begin{array}{l}\text { RFID-enabled warehouse } \\
\text { management system }\end{array}$ & $\begin{array}{l}\text { Provides RFID-enabled automated storage and retrieval } \\
\text { mechanism without any human intervention, majorly to } \\
\text { maximize efficiency in material-handling operations and } \\
\text { minimize operational costs }\end{array}$ \\
\hline
\end{tabular}




\section{Table 5. RFID/loT usage in healthcare}

\begin{tabular}{|c|c|c|c|}
\hline $\mathbf{S} / \mathbf{N}$ & Publication name & System architecture proposed & Principle of operation \\
\hline 1. & $\begin{array}{l}\text { Improving RFID adoption in } \\
\text { Taiwan's healthcare industry based } \\
\text { on a DEMATEL technique with a } \\
\text { hybrid MCDM model [22] }\end{array}$ & $\begin{array}{l}\text { RFID based patient and asset } \\
\text { management. }\end{array}$ & $\begin{array}{l}\text { RFID was used for to automate patient check-in and other } \\
\text { outbound logistical processes }\end{array}$ \\
\hline 2. & $\begin{array}{l}\text { Design framework for sensors and } \\
\text { RFID tags with healthcare } \\
\text { applications [24] }\end{array}$ & $\begin{array}{l}\text { Sensor and RFID framework in } \\
\text { healthcare domain }\end{array}$ & $\begin{array}{l}\text { Proposes a framework suitable for RFID and Sensor usage in } \\
\text { healthcare domain }\end{array}$ \\
\hline 3. & $\begin{array}{l}\text { Adaptive knowledge-based system } \\
\text { for health care applications with } \\
\text { RFID-generated information [25] }\end{array}$ & $\begin{array}{l}\text { An adaptive knowledge-based system } \\
\text { framework for health care using RFID } \\
\text { generated information }\end{array}$ & $\begin{array}{l}\text { Uses RFID technology to track the movement of bottled gas } \\
\text { within the hospital so as to ensure their delivery back to the } \\
\text { pharmacy after usage. }\end{array}$ \\
\hline 4. & $\begin{array}{l}\text { RFID-initiated workflow control to } \\
\text { facilitate patient safety and } \\
\text { utilization efficiency in operation } \\
\text { theater [26] }\end{array}$ & $\begin{array}{l}\text { RFID based a Patient Advancement } \\
\text { Monitoring System }\end{array}$ & $\begin{array}{l}\text { With a view to enhance management efficiency, RFID tags was } \\
\text { used to create multiple data entry ports across different wards so } \\
\text { as to manage the progress of operations, patient localization, } \\
\text { identity verification, and peri-operative care. }\end{array}$ \\
\hline 5. & $\begin{array}{l}\text { A comprehensive RFID solution to } \\
\text { enhance inpatient medication } \\
\text { safety [27] }\end{array}$ & Inpatient Safety RFID system & $\begin{array}{l}\text { Uses RFID to monitor inpatient's medication process by fixing } \\
\text { RFID wristbands to inpatients arms and to their unit-dose } \\
\text { medications }\end{array}$ \\
\hline 6. & $\begin{array}{l}\text { Application of Radio Frequency } \\
\text { Identification (RFID) in Dairy } \\
\text { Information Management [28] }\end{array}$ & $\begin{array}{l}\text { RFID Scalable Medical Alert } \\
\text { Response Technology }\end{array}$ & $\begin{array}{l}\text { Uses RFID to monitor vital signs and locations of certain classes } \\
\text { of ambulatory patients in overcrowded emergency departments } \\
\text { and at disaster scenes }\end{array}$ \\
\hline
\end{tabular}




\subsection{Construction Domain}

RFID has been introduced in construction to make easier, and even automatic, a large variety of processes during the lifecycle of a building. During the construction process, thousands of materials and a crew of workers, equipped with tools and vehicles, are permanently changing their position in the jobsite. Controlling the location of resources [30] and materials [31] mainly in the organization of the storage area or the control of deliveries helps to improve the productivity in building erection and to increase the safety of workers. To ensure effective monitoring of workers, equipment and enforce continuous construction process, several technologies that could be incorporated with RFID were presented in [30] such as positioning systems (GPS) [32,33]; vision systems (camera) $[34,35,36,37,38]$. A combination of RFID, GPS, Personal Digital Assistant (PDA) and GPRS were employed for the automatic control and real-time monitoring of dam material transport truck watering in [39]. The developed system automates the control of watering operations according to the volume carried by each truck and the type of dam material loaded. It also monitors continuously the whole process of truck watering. RFID tags and integrated control module were mounted on each truck, in addition valve control module, signal light module, wireless communication module, job-site alert module and a RFID reader were fixed on the moveable watering station. The database, application server and monitoring PCs are located in the supervision engineers' office building, about $20 \mathrm{~km}$ far away from the job-site; and PDAs are held by supervision engineers at the job-site. With these total compliance of staffs on the construction site was achieved. Furthermore, a mobile passive RFID portal for automated and rapid control of Personal Protective Equipment (PPE) on construction sites was implemented in [39]. The mobile passive RFID was used to enforce PPE compliance of personnel at construction site. When such gates are positioned at the entrance or within construction sites and once low-cost passive RFID tags are embedded or attached to PPE, automatic site access, time recording, and completeness control can be performed. These improve the logistics of the existing compliance checking process and provide users with timely feedback. The approach demonstrated how the safety process, especially the awareness among personnel wearing PPE, can be pro-actively managed and controlled.
The feasibility of implementing an RFID system for the manufacturing and assembly of crankshafts was presented in [40]. The proposed solution involved the attachment of bolts with embedded RFID functionality by fitting a reader antenna reader to an overhead gantry that spans the production line and reads and writes production data to the tags. The manufacturing, assembly and service data captured through RFID tags and stored on a local server, could further be integrated with higher-level business applications facilitating seamless integration within the factory. For the monitoring, traceability and tracking of crankshafts throughout the relevant machining and assembly processes, the design incorporated an antenna reader (i.e. transmitter and receiver), which was held by a bracket to the gantry gripper and bolt transponders affixed to the crankshaft. Depending on the antenna reader chosen, typical power outputs are normally $1 \mathrm{~W}$, frequency ranges of $886-928 \mathrm{MHz}$ (EU-US) and read/write ranges of $6 \mathrm{~cm}$ to $3 \mathrm{~m}$ with a cone cover area of about $70^{\circ}$ (refer to Section V). A gantry robot was programmed with the complete process routing of the crank, enabling an embedded RFID tag attached to each crankshaft was used to record the complete process history. Since the gantry robot was used as a common transfer element for all of the manufacture operations, this option, addresses the process gaps left by other tracking systems such as DataMatrix, which can only collect limited process history information since recordings are made only at a small number of discrete points within the process.

\subsection{Education}

The impact of RFID is gradually being felt in the education sector, besides the tracking of assets, it has been widely used in enforcing students' compliance and comportment during examinations, staffs compliance to time constraint activities. RFID based attendance and assessment system with wireless database records was presented in [41]. Both wired and wireless control medium for automation were employed. A mobile phone with an android based operating system was used to monitor the database wirelessly by means of TCP/IP which gave easy access for communication within an indoor proximity, for outdoor larger proximity, GSM module was used. The modules were further interfaced with programmable controller via serial communication (RS232). The programmable controller performs the actuation 
on signal received from either communication channel by making the actuators perform their desired task. The controller was programmed to perform actuation as per requirement of the user. The controller was also programmed to have duplex communication with the actuators thus getting feedback if any error occurs in the operation. Equally, a RFID-based student's attendance management system was developed and deployed in [42]. It was aimed at eliminating time wasted during manual collection of attendance while providing an opportunity for the educational administrators to capture face-toface classroom statistics. Every student was given a specific RFID tag and is expected to attend the lecture through entrance door, a serial number (related to each student's matriculation number) of tag is associated with the student database entry. So every time a student uses his/her card, the entries will be entered into the database with the time stamp. The tag is activated when it passes through a radio frequency (RF) field ( $125 \mathrm{kHz}$ in this case), which is generated by the antenna embedded within the reader box. The program checks whether the tag is valid or not. If the tag is valid, it will continue to the database program and registers the student's attendance for the course. If the tag is invalid, the program gives a notification that the tag has not been registered to any student and requires the user to either supply a valid tag. Due to financial constraint, the RFID attendance design application used a passive tag and thus for every class, students would have to bring their tags close to the reader (about $10 \mathrm{~cm}$ from the reader). A similar RFID based attendance system was also developed in [43].

Computer aided school administration system using RFID technology was developed in [44]. RFID usage was extended to provide automatic students and staff identification, class/ laboratory/library attendance management, static/dynamic authorization, submission of warnings/announcements and e-money usage. For students, staff and visitors identification, RFID readers attached turnstiles are used to allow one person to pass at a time. When a valid pass occurs, using the information sent by the reader, the developed application identifies the person. As users are asked to use their tags in every pass, the RFID system was further used to count the number of people entering or leaving the school on a daily basis. Visitors are provided with temporary tags and their personal information and purpose of visiting the school is recorded. For static authorization management, RFID was used as an electronic key to control access to classrooms or laboratories within the school building. Authorization for tag bearers are defined separately or in groups to enable or disable their access to specified area. To extract attendance information, an RFID reader is located near the classroom, laboratory or library door and students are asked to use their tags as they enter or exit. Additionally, RFID tags were also used like a credit card to provide payment without using cash (e-Money). Canteens, cafeterias and refectories are places within the school where e-Money could be used. RFID tags were also deployed to secure books in the library and ensure that certain books were not taken beyond some sections in the library $[43,44,45,46]$. The tags with their readers were programmed to trigger an alarm should a user attempt to sneak out a book or take a book beyond the required region.

\subsection{Other Application Areas of RFID}

RFID has received a growing attention and has gotten a wide range of applications in other areas such as agriculture, Renewable energy harvesting, sports (for tracking golf balls, event timing, gaming chips e.t.c), for rectifying logistic issues in Government and military, for human identification as in digital and electronic IDs, for smart cards in Finance sectors, indoor object tracking [47] etc. A dairy information management system was developed in [48]. The management system based on RFID leveraged on the real-time data exchange prowess between electronic tags and readers to identify and record the weight, feed intake, physical activity and milk yield of each archived dairy cows. The physical and chemical indicators of milk and other valuable data could easily help farmers to record, monitor and analyzed changes and growth trend of dairy cows. Computer software packages will automatically analyze and deal the data that collect from each dairy cow, and compare with the standard data of the dairy cow' growth stage. Once the data exceed the health warning line given by computer data system, management system would identify automatically and create report and feed back to the manager in time, so as to check cattle targeted and adjust the feed structure and supply. Tracking and tracing of individual cow with corresponding RFID tags and readers was also reported in $[49,50]$ 
A renewable energy harvesting for wireless sensors using passive RFID tag technology was developed in [51]. This was based on the fact that a RFID reader module emits signals of certain frequency wirelessly in the form of a sine wave. This signal was captured by the passive tag antenna. The antenna then sends this signal to its built-in Integrated Circuit (IC). The IC contains a rectifier unit, which converts the $A C$ signal to DC so that it can be used to drive its internal circuitry. The passive tag itself barely generates enough power to drive its own circuitry. For that reason, passive tags have such poor read ranges. So, in order to improve the range, the transmitted AC signal from the RFID reader must be amplified. Assuming the reader signal was fixed and cannot be modified, the boost in power must come from a different source. To make the technology more environmentally friendly, a solar panel system was introduced to serve as a supplementary power source. The solar panels supply DC power, so an oscillator was used to convert it to a frequency that the tag can receive. The signal was then forwarded to the antenna where it combines with the signal transmitted from the RFID reader.

\section{CONCLUSION}

Though, the use of RFID is inexhaustible, this article gave an insight into the current application areas and trends of RFID technology. It further shows the role RFID will play in achieving the vision of loT which aimed at achieving the connectivity of every object around us. As no technology is exclusively flawless in all ramifications, further researches need to be done to address interference issues that may arise when a RFID reader attempts to read many readers or a specific reader among multiple readers should be further looked into towards enhancing the performance and general acceptability of RFID technology. The processing capacity of RFID readers need to be more enhanced so as to be suitable for processing complex tasks. Finally, efforts at overcoming the limitations highlighted and enforcing the suggestions provided in this paper must be put in place.

\section{COMPETING INTERESTS}

Authors have declared that no competing interests exist.

\section{REFERENCES}

1. E. Borgia. The internet of things vision: Key features, applications and open issues, Computer Communication. 2014; 54(1):1-31.

2. Julien Mineraud, Oleksiy Mazhelis, Xiang $\mathrm{Su}$, Sasu Tarkoma. A gap analysis of Internet-of-things platforms. Computer Communications. 2016;(89):5-16.

3. Somayya Madakam. Internet of Things: Smart things. International Journal of Future Computer and Communication. 2015;4(4):250-253.

4. Lea R, Blackstock M. CityHub. A cloud based loT platform for smart cities", in: proceedings of the IEEE $6^{\text {th }}$ international conference on cloud computing technology and science (CloudCom). 2014;799-804.

5. Tsai CW, Lai CF, Chiang MC, Yang L. Data mining for internet of things: A survey. IEEE Commun. Surv. Tutor. 2014; 16(1):77-97.

6. Shu Yinbiao, Kang Lee, Peter Lanctot. Internet of things: Wireless sensor networks. International Electrotechnical Commission white paper; 2015.

7. Presser $M$, Gluhak $A$. The internet of things: Connecting the real world with the digital world. EURESCOM mess@ge The Magazine for Telecom Insiders. 2009; (1).

8. Buettner M, Greenstein B, Sample A, Smith JR, Wetherall D. Revisiting smart dust with RFID sensor networks. In: Proceedings of ACM HotNets, Calgary, Canada; 2008.

9. Stephen A. Weis. RFID: Principles and Applications. MIT CSAIL; 2016.

10. Klaus Finkenzeller. RFID handbook: Fundamentals and applications in contactless smart cards, Radio $f$ requency Identification and near-field communication. Third Edition, John Wiley \& Sons, Ltd; 2010.

11. Elisabeth Ilie-Zudor, Zsolt Kemény, Péter Egri, László Monostori. The RFID technology and its current applications. In proceedings of the modern information technology in the innovation processes of the Industrial Enterprises-MITIP. 2006;2936.

ISBN 9638658657 
12. Diana Segura Velandia $M$, Navjot Kaur, William Whittow G, Paul P. Conway and Andrew A West (2016), "Towards industrial internet of things: Crankshaft monitoring, traceability and tracking using RFID. Robotics and Computer-Integrated Manufacturing. 2016;41:66-77.

13. Somayya Madakam. Internet of things: Smart things. International Journal of Future Computer and Communication. 2015;4(4):250-253.

14. Villanueva F, Villa D, Moya F, Santofimia M, Lopez J. Internet of things architecture for an RFID-based product tracking business model. In: Proceedings of $6^{\text {th }}$ Innovative Mobile and Internet Services in Ubiquitous Computing (IMIS). 2012;811816.

15. Francesco Rizzo, Marcello Barboni, Lorenzo Faggion, Graziano Azzalin, Marco Sironi. Improved security for commercial container transports using an innovative active RFID system. Journal of Network and Computer Applications. 2011;34:846852.

16. Provotorov A, Privezentsev D, Astafiev A. Development of methods for determining the locations of large industrial goods during transportation on the basis of RFID. Proceedings of the International Conference on Industrial Engineering. Procedia Engineering. 2015;129:10051009.

17. Choi SH, Yang B, Cheung HH, Yang YX. RFID tag data processing in manufacturing for track-and-trace anti-counterfeiting. Computers in Industry. 2015;68:148-161.

18. Jaroslav Masek, Peter Kolarovszki, Juraj Camaj. Application of RFID technology in railway transport services and logistics chains. Proceedings of the $9^{\text {th }}$ international Scientific Conference Transbaltica. Procedia Engineering. 2016;134:231-236.

19. Rodrigo Oliveiraa $R$, Ismael Cardosoa MG, Jorge LV. Barbosaa Cristiano A. da Costaa, Mario Prado P. An intelligent model for logistics management based on geofencing algorithms and RFID technology. Expert Systems with Applications. 2015;42(15-16):6082-6097.

20. Musa A, Gunasekaran A, Yusuf Y, Abdelazim A. Embedded devices for supply chain applications: Towards hardware integration of disparate technologies. Expert Systems with Applications. 2014;41:137-155.
21. Saleh Alyahya, Qian Wang, Nick Bennett. Application and integration of an RFIDenabled warehousing management system - a feasibility study. Journal of Industrial Information Integration. 2016;4:15-25.

22. Ming-Tsang Lu, Shi-Woei Lin and GwoHshiung Tzeng. Improving RFID adoption in Taiwan's healthcare industry based on a DEMATEL technique with a hybrid MCDM model. Decision Support Systems. 2013; 56:259-269.

23. Lee LS, Fiedler KD, Smith JS. Radio frequency identification (RFID) implementtation in the service sector: A customerfacing diffusion model. International Journal of Production Economics. 2008; 112(2):587-600.

24. Mark Gaynor, Jason Waterman. Design framework for sensors and RFID tags with healthcare applications. Health Policy and Technology. 2016;5(4):357-369.

25. Yannick Meillera, Sylvain Bureaua, Wei Zhoua, Selwyn Piramuthu. Adaptive knowledge-based system for health care applications with RFID-generated information. Decision Support Systems. 2011;51(1):198-207.

26. Charles Liu $\mathrm{CH}$, Chia-Huang Chang, MuChun Su, Hsueh-Ting Chua, Sheng-Hui Hung, Jau-Min Wongb, Pa-Chun Wang. RFID-initiated workflow control to facilitate patient safety and utilization efficiency in operation theater. Computer Methods and Programs in Biomedicine. 2011;104(3): 435-442.

27. Pedro Peris-Lopez, Agustin Orfila, Aikaterini Mitrokotsa, Jan CA, van der Lubbe. A comprehensive RFID solution to enhance inpatient medication safety. International Journal of Medical Informatics. 2011;80:13-24.

28. Wu Hong-da. Application of Radio Frequency Identification (RFID) in Dairy Information Management. Journal of Northeast Agricultural University. 2012; 19(1):78-81.

29. Zhengxia $W$, Laisheng $X$. Modern logistics monitoring platform based on the internet of things. In International conference on intelligent computation technology and automation. 2010;2:726-731.

30. Su X, Li S, Yuan C, Cai H, Kamat V. Enhanced boundary condition based approach for construction location sensing using RFID and RTK 
GPS. Journal of Construction Engineering and Management. 2014; 140(10):401-404.

31. Goodrum PM, McLaren MA, Durfee A. The application of active radio frequency identification technology for tool tracking on construction job sites. Automation in Construction. 2006;15(3):292-302.

32. Cai H, Andoh AR, Su X, Li S. A boundary condition based algorithm for locating construction site objects using RFID and GPS. Advanced Engineering Informatics. 2014;28(4):455-468.

33. Costin A, Pradhananga N, Teizer J. Passive rfid and bim for real-time visualization and location tracking. Proceedings of Construction Research Congress. 2014;169-178.

34. Huang RY, Tsai TY. Development of an RFID system for tracking construction residual soil in Taiwan. Proceedings of the $28^{\text {th }}$ International Symposium on Automation and Robotics in Construction; 2011.

35. Fumio $H$, Yasushi $Y$, Shinichi $E$. Development of digital photo system using RFID technology in plant construction management. Proceedings of the $25^{\text {th }}$ International Symposium on Automation and Robotics in Construction; 2008.

36. El-Omari S, Moselhi O. Integrating automated data acquisition technologies for progress reporting of construction projects. Automation in Construction. 2011;15(3):292-302.

37. Ko $\mathrm{CH}$. RFID-based building maintenance system. Automation in Construction. 2009; 18(3):275-284.

38. Rebolj D, Babič Nu, Magdič A, Podbreznik $P$, Pšunder $M$. Automated construction activity monitoring system. Adv. Eng. Inform. 2014;22:493-503.

39. Agnes Kelma, Lars Laußata, Anica MeinsBeckera, Daniel Platza, Mohammad Khazaeea J, Aaron Costinb M, Manfred Helmusa. Mobile passive radio frequency identification (RFID) portal for automated and rapid control of personal protective equipment (PPE) on construction sites. Automation in Construction. 2013;36:3852.

40. Diana M. Segura Velandia, Navjot Kaur, William Whittow G, Paul Conway P, Andrew West A. Towards industrial internet of things: Crankshaft monitoring, traceability and tracking using RFID. Robotics and Computer-Integrated Manufacturing. 2016;41:66-77.

41. Sarmad Hameed, Syed Muhammad, Taha Saquib, Faraz Junejo, Moez ul Hassan Radio frequency identification (RFID) based attendance and assessment system with wireless database records. Procedia - Social and Behavioral Sciences. 2015;195: 28892895.

42. Arulogun OT, Olatunbosun A, Fakolujo OA, Olaniyi OM. RFID-based students attendance management system. International Journal of Scientific \& Engineering Research. 2012;4(2):1-9.

43. Krenare Pireva $R$, Jeton Siqeca, Shkelqim Berisha. RFID: Management system for students' attendance. $5^{\text {th }}$ Workshop on International Stability, Technology, and Culture, The International Federation of Automatic Control, Prishtina, Kosovo; 2013.

44. Forbes Gibb, Clare Thornley, Stuart Ferguson, John Weckert. The application of RFIDs in libraries: An assessment of technological, management and professional issues. International Journal of Information Management. 2011;31:244251.

45. Petra Düren. Implementation of a library RFID management system. Leadership in Academic and Public Libraries. 2013;2743.

46. Yogesh Dwivedi K, Kawaljeet Kaur Kapoor, Michael Williams D, Janet Williams. RFID systems in libraries: An empirical examination of factors affecting system use and user satisfaction. International Journal of Information Management. 2013;33(2):367-377.

47. Soonuk Seol, Eun-Kyu Lee, Wooseong Kim. Indoor mobile object tracking using RFID. Future Generation Computer Systems. 2016;1-15.

48. Wu Hong-da. Application of radio frequency Identification (RFID) in dairy information management. Journal of Northeast Agricultural University. 2012; 19(1):78-81.

49. Oanette M. Secure animal identification and source verification.

(Accessed on $3^{\text {rd }}$ September 2016)

Available: http://www.optibrand.com 
50. Philips C. Development and application of animal electronic identification.

Available:http://www.chinanews.com.

cn/news/2004/2004-10-030

260490602.shtm

(Accessed on $3^{\text {rd }}$ September 2016)
51. Raquib M, Ferdous D, Ahmed Wasif Reza, Muhammad Faisal Siddiqu. Renewable energy harvesting for wireless sensors using passive RFID tag technology: A review. Renewable and Sustainable Energy Reviews. 2016;58:1114-1128.

(0) 2016 Arulogun et al.; This is an Open Access article distributed under the terms of the Creative Commons Attribution License (http://creativecommons.org/licenses/by/4.0), which permits unrestricted use, distribution, and reproduction in any medium, provided the original work is properly cited.

Peer-review history:

The peer review history for this paper can be accessed here:

http://sciencedomain.org/review-history/17616 